\title{
Postcolonial Human Identity in Mahesh Dattani’s Select Plays
}

\author{
G. Jeyalakshmi \\ Department of English \\ Govindammal Aditanar College for Women \\ Tamil Nadu, India \\ lakshmilingam1973@gmail.com
}

\begin{abstract}
Mahesh Dattani is rightly regarded by the international Herald Tribune as one of the best and the most serious playwrights writing in English, His plays expose the violence of private thoughts and the hypocricy of public morality, Dattani wants to get rid of all kinds of evils in the society which spoil the degnifid life. All the atrocities in the name of religion, class, race, or gender can be eradicated if a person is able to understand the power of the human nature. It is not intelligent to be submissive to the cruelties of the oppressor and demising human dignity. This paper analyses a few plays of Dattani to prove that Dattani is against both the atrocities of the dominating and the submissiveness of the dominated in order to attain a dignified life with self -identity.
\end{abstract}

Keywords: self-identity, submissiveness, resistance and postcolonial

The first phase of Indian drama after Independence was marked by the notification of western thoughts and modes though there were struggles to come out of their influences. Middle class drawing room situations through the experimentation in expressionism, absurd theatre and various dramatic devices were extensively used to express native situations. It so happened at times that this attempt at the notification of the west ended up with the 
westernization of the native, which became an expression of neo-colonization. As a reaction to this there started a vigorous exploration of the native culture and more specifically the folk culture that could provide context and substance for postcolonial Indian identity. This situation has been aptly summed up by Girish Karnad when he says:

My generation was the first to come of age after India became independent of British rule. It therefore has to face a situation in which the tensions implicit until this had come out in the open and demanded to be resolved without apologia or self-justification, tensions between the cultural past of the country and its colonial past, between the attraction of western mode of thought and our own tradition, and finally between the visions of the future that opened up once the common course of political freedom was achieved. (21)

This paper aims at exploring the idea that the select plays of Dattani reflect the postcolonial socio- political scenario which has created spaces to identify the invisible identities of the marginalized sections of society and to promote human dignity and divinity by uplifting self-respect and individuality. Dattani wants to articulate the voice of those whose identity remain unacknowledged under the hegemonic and authoritative voice of the elitists, showing superiority in the name of caste, gender, race, religion, economic status or any other paradigm of the manifestation of power. In socio-political context, the centremargin binary includes the awareness of living conditions, language construction, social recognition, power structure and the control over the resources of productivity. In the words of Gayatri Spivak marginality can be acknowledged in terms of 'silence and speech'. With the persistent annals of subordination, the marginalized groups were devoid of mental strength of self-affirmation. They were forced to lead the life of subalterns. In view of Spivak subalternity denotes the general attribute of subordination in south Asia whether this expressed in term of caste, class, gender, religion or any other way. There have been 
organized collective efforts to make the representation of the conditions of oppressions and to stir the consciousness about their suppressed self so that they might be inspired to seek spaces in the mainstream of life. In this process, the emphasis is not on political liberation only but also on the emancipation from the psychological impact of oppression. It anticipates the shift of margins and proclaims the emergence of new man who can assert himself against irrational domination of elitists' ideologies. Nandy, the eminent postcolonial critic, postulates that the psychological liberation is more significant than socio and political liberation:

The colonialism colonizes minds in addition to bodies and releases forces within colonized societies to alter their cultural priorities once and for all. In the process, it helps to generalize the concept of the modern west from a geographical entity to a psychological category. The west is now everywhere within the west and outside in structures and in minds. (83)

Every individual possesses the divine sparks of human sensibility and its willful suppression might lead to volcanic eruptions. In the postcolonial literature, the critics and writers directed their efforts to restore the humanity of those who are dehumanized and are subjected to all humiliations and injustice. Shiller defines it as a method to acknowledge the humanity of dehumanized. In his view, each individual human being carries within him potentially and perceptively an ideal man, the archetype of human being, and it's his life's task to be, through all his changing manifestations, in harmony with the unchanging unity of this ideal.

Dattani launched his dramatic voyage to find out a way of 'Decolonizing Theatre' escaping the shadows of as Mee said, politically driven search for an indigenous aesthetic and dramaturgy. Deviating from the conventions of conventional morality within the pages of his plays, Dattani reconstructs the spaces for marginalized groups of society. He admits that each individual wants to be a part of society, of the mainstreams but it must be acknowledged that 
it is a forced harmony. Within the dramatic texts of Dattani, the voices of marginalized groups like the minority religious groups, community of Eunuchs, the victims of AIDs, gays and lesbians, and women find expression with a view to get their individuality.

It is obvious that Dattani looks at the human aspect of the characters whether they are women, eunuchs or people belonging to certain religions. It is his desire that human beings of any class, race or family must be respected without causing any stigma on their dignity as being born into a particular class, religion or race is not their sin. Hence it is clear that he is against the colonial attitude of treating the orient as the 'other' and 'subaltern'. Like typical postcolonial writer, he wants to wipeout the very existence of the 'other' as a colonial agency. The conception of the orient as a backward class is irrational. Similarly in the postcolonial era, everyone is compelled to abandon the culturally customary ways of thinking which is considered inferior and to adopt the western ways of thinking, the superior. Dattani is of the view that any way of thinking whether it is eastern or western can be followed provided it leads to a dignified life.

Dattani's longing for the dignified life of all the people makes the characters of his plays lead a life with self-respect and individuality which are the main elements of postcolonial literature. In most of the plays, the characters are propelled on the right path with self-respect. In Where There is a Will, all the characters, including the chauvinist, Hasmukh, realize the greatness of their own selves. They also understand the uniqueness of their individuality in order to live a meaningful life with satisfaction and happiness. In all the other plays which are taken for analysis, most of the characters have self-respect and individuality.

Dattani wants all kinds of evils in the society which spoil the dignified life to be done away with. All the atrocities in the name of religion, class, race or gender can be eradicated 
if a person is able to understand the power of his human nature. It is not intelligent to be submissive to the cruelties of the oppresser and thereby demising human dignity.

Discrimination, one of the main evils of the society, is the main idea against which all postcolonial writers fight. It destroys the happiness of the family and that of the society depriving the human beings of their dignity. The discrimination between the male and the female, between the religious groups, between the margnalised and others, between the self and the other are the main concerns of the plays of Dattani. It is this discrimination which has ended in the death of Tara in Tara, the death of the poojari in Final Solutions, the death of the old woman in Bravely Fought the Queen, the death of Ratna's son in Dance Like a Man and the death of Hasmukh in Where There is a will. In the case of Tara and Bravely Fought the Queen there is a dichotomy between the male and the female. In Final Solutions, the dichotomy between Hindus and Muslims has led to the riot. In Where There is Will and Dance Like a Man, self-other dichotomy between the patriarch and the other members of the family has spoiled the happiness of the family.

Dattani is against both the atrocities of the dominating and the submissiveness of the dominated. The unnecessary submissiveness of the dominated is as dangerous as the arrogance of the dominating. Submissiveness will only lead to more and more domination and cruelties.

Hence Dattani wants the dominated to resist, which is one of the main features of post colonialism. Resistance is shown at first at the inner world of the characters, then through the words and finally through action. In Final Solutions, resistance becomes rebellious but in Tara, Bravely Fought the Queen and Dance Like a Man, it does not go beyond word-quarrel. By resisting Tara has proved that she has equal rights with Chandan and Bharathi has proclaimed her equality with her husband. Dolly and Alka in Bravely Fought the Queen are able to make their husbands understand the injustice done to them. In Where There is a Will 
resistance of Ajith has been used to prove his individuality. Sonal's resistance shows her equality with Hasmukh. Preeti's resistance through exchanging the tablets of Hasmukh with her own vitamin tablets is highly venomous. Dattani suggests that this kind of resistance is destructive and not productive. Hasmukh's resistance through the 'Will' has changed the purposeless life of everyone into a respectful and happy life. Kiran's resistance against her husband by having an illegal affair with Hasmukh has given her only the tactics of survival though it gives financial support to her and moral support to Hasmukh's family. In Final Solutions, Javed's resistance against the injustice done to the minorities has made others realize the importance of unity in diversity. In the patriarchal system it is the husband who dictates the terms and conditions to his wife. Bharati's husband is so cruel, vindictive, arrogant and revengeful that he does not permit his wife to donate her kidney to Tara. When Bharati insists on it, Patel bluntly refuses and does not permit his wife to take any 'major decision' in the family. If the secret of the separation of Tara and Chandan is to be disclosed, it should be done through him and not through her. "If at all they must know, it will be from me. Not from you". (345) Patel goes on giving so much of psychological torture to his wife that it ultimately results in her mental breakdown. Bharati is finally hospitalized and as Roopa reports, “Finally gone loony. Stark naked mad."(358) Whereas Bharati constantly suffers from her sense of guilt, Patel is bent upon rubbing her nose in.

The social conventions of gender spoil the grace of life for both male and female. This is the focal point of the play Dance Like a Man. Jairaj and Ratna live within a patriarchal structure, domain of the patriarch Amritlal, Jairaj's father. Dance for him is the prostitute's profession, improper for his daughter-in-law and absolutely unimaginable for his son. For him individual identity of Jairaj was not much significant. He realizes Jairaj's mission and he manages a conspiracy with Ratna, his own daughter-in-law. He convinces Ratna that her 
success as dancer can be brightened if she helps Jairaj in bringing him out of his obsession and helps in making him a 'manly man'.

When Amirtlal plays a trick on Ratna by permitting her to dance, and stopping Jairaj from dancing, he is a typical embodiment of Hegemonic Masculinity. Men are confused with their social masks for existence and they are destroying themselves while fulfilling the traditional definitions of masculine behaviour. They set their sails by these irrational definitions. The reality is always approached through these veils of gender expectations. The conditional conspiracy of Amirtlal and Ratna spoils both Jairaj 'the artist' and Jairaj 'the man'.

Amritlal with his power of money exploits the womanhood of Ratna by depriving her from the association of a real man. Ratna's character can be analyzed under female masculinity. She values her identity as a dancer far better than her identity as a mother and a wife. Dattani emphasizes that the organizational rules and institutional laws have to be rewritten as gender neutral. It is the interactional and cultural dimension of gender that has yet to be tackled with a social change. He seems to insist this point by representing the contemporary life situations of middle class families and shows the gender inequality through his unexpressed and unspoken characters.

Refusing to dance to the tune of men Dattani's women characters seek to break the age-old silence and to stand on their own legs. Tara, Dolly, Alka, Kiran, Sonal, Preeti, Hardika, Smita, and Uma have decided to cast off their traditional roles of living under the shades of the male members of the family. They are ready to revolt against all kinds of tortures and restrictions in the society. They are able to assert their individual identity refusing to submit to the dictates of male-dominant society.

Some of the women characters of Dattani have discovered that they are free to create their own selves. This discovery constitutes a new identity in the cultural hierarchy of the 
male world. Hence the women are able to reconstruct the cultural 'self' by using as their weapon, all the attributes assigned to them by the male 'gaze' to push them to the margin. With these attributes, women have created a unique language of their own, re-presenting themselves and interrogating the representation of 'woman' in the male discourse. Simon De Beauvoir in her book Second Sex says, "He (man) is the subject, he is the absolute - she is the other."(xix) It is from this otherised position that the woman has tried to understand and realize the manner in which her body and her relation to the world are modified through the action of others than herself.

Infact both women and members of other marginalized groups are subject to the discriminatory social practice in India in a similar way. It is on the ground of this discrimination that women and members of other marginalized sections of the society can be seen operative in the society in (i) not granting women/marginal 'other' the autonomy of choice (ii) meting out atrocities on them through verbal and physical violence (iii) silencing of their existence by barring representation and (iv) obliteration of their individual identities. The thingfication of individuals vis-à-vis communities has long been in operation in human societies under the control of power and to safeguard the interest of the powerful. Thingfication is executed through removal of human dignity, individual as well as collective will and rights from subjects on ground of gender and caste to treat those 'thingified' individuals merely as recipient of action. Grounds such as caste, gender, religion and socioeconomic contexts are integrated to form the network of control of the powerful over the ones without legitimized power. The process of control through thingification can be seen as what Said identifies as the 'guise of filiations'. This can be found in Dattani'sSeven Steps around the Fire, Final Solutions, Bravely Fought the Queen, Tara, Where There's a Will, and Thirty Days in September. 
Dattani is neither the follower of unwanted convention of Indian nor the blind worshipper all the aspects of oppressor's culture. He encourages the demolition of false prejudices and conventions. He pleads for individual's right to live his or her life according to his or her own right. One may fail or come to grief but at least one would be daring to face life on one's own. He longs to give identity to everyone in the society regardless of sex, religion, race etc. As a dramatist, he himself has achieved an identity for himself with the help of a variety of innovative techniques and he has given sixty million English speaking Indians an identity.

There are many references to equality in Dattani's different texts: Chandan in Tara says: "It's all the same. You. Me. There's no difference"(361) and Javed in FinalSolutions says: "We are not very different. You and Me." (214) But there are many situations where equality cannot be maintained. For example, the possibility of maintaining equality between the dead pojari'sfamily and his murderer's family in Final Solutionsis a question. Similarly equality between man and woman is only an illusion. It cannot be easily attained. Not only in the case of man-woman relationship but also in the relationship between any two humanbeings, equality is not possible because every man looks at others either as inferior to him or as superior to him.He is subaltern in many cases and makes others subaltern in many other cases. Hence equality cannot be easily attained. It can only be dreamt of. Man is imperfect and discrimination is part of his imperfection. As Dattani insists on individuality of a person, individuality and equality cannot be maintained simultaneously. But every individual must be able to respect others with their individualities to attain the intellectual maturity for equality; it will take as much years as it took for man's evolution from monkey.

Dattani's plays are performance oriented addressing bold themes and grave issues pertaining to the urban middle class Indian society. As a social realist he deals with subjects that are rooted in contemporary social, political and cultural Indian milieu. From religious 
fundamentalism, to child sexual abuse, to gender roles, to homosexuality, to arranged marriage and from deseases to natural calamities, his plays have confronted issues that could cause many an Indian audience to squirm. Hence Dattani's plays can be examined to bring out the social context prevalent in them.

The notions and experiences that shaped the different conceptual categories of postcolonialism, as illustrated in Dattani's plays, are very relevant in the current World scenario. The discriminative concerns that form a fundamental theme of his plays are quite significant with reference to the contemporary political and social situation.

The distinction and discrimination among human beings on the basis of the dichotomy between the powerful and the powerless can be perceived in all the societies, that is,western and oriental alike, even when it is claimed that such disparities are getting diminished due to the campaigns of eminent personalities such as Mahatma Gandhi, Martin Luther King, Nelson Mandela, etc. In fact, these distinctive considerations on the basis of various status have taken different shapes and manifestations in the so-called advanced societies in the form of rich/poor, upper caste/lower caste, powerful/powerless, ruler/ruled divisions, etc.

Similarly, the claim that colonialism has ended can be seen as a pretext of western ideologies to mislead the world. The fact that capitalism in the form of corporate giants has undermined the economic balance of the Third World countries cannot be underestimated. This has ultimately resulted in the contemporary cleavage between the rich countries and poor countries, similar to the dichotomy between the upper classes and the lower classes. Thus, strong colonial tendencies are at work in the world today on the political, social and cultural levels. Class conflicts of a grave nature like this are the feature of the post-colonial world even though the paradigms of resistances of the underprivileged and powerless can be observed in one form or another as could be identified in the plays of Dattani. The attempts to dominate the world through new moralities are still going on and it is the formalistic 
approach to colonialism that can be seen in the claim that it has come to an end by devolution of power to the once colonized countries. The western domination of the orient has taken a new shape with one difference that the previous direct colonial approach of the westerners has been reorganized and restructured.

The destiny and opinion of the world are shaped by the imperial culture of the west with its deliberate constructions of new dichotomies between self and other. These neocolonial tendencies can be found in India in the form of hegemic attitude of one group over the other groups in the society. The plays of Dattani become relevant in the present situations with their political, social and cultural issues that are still significant in the modern world.

Drama was the medium of Dattani for presenting the resistances of the marginalized. However, his observations have universal relevance even today because the world is now enduring the effects of diversified dichotomies between the self and the other, the colonizer and the colonized, the master and the self, the state and citizens at unimaginable and sometimes uninterpretable levels. It is clear that Dattani's plays have contemporary significance in the sense that his plays deal with different aspects of postcolonial experience that continue to affect the contemporary world in various dimensions and at various levels. 


\section{Works Cited}

Primary Sources

Dattani, Mahesh. A Tale of a Mother Feeding Her Child. Collected Plays II. By Dattani. New Delhi: Penguin, 2010. 558-572.

--- "Bravely Fought the Queen.” Collected Plays. By Dattani. New Delhi: Penguin, 2000. 227-315.

---. “Dance Like a Man.” Collected Plays. By Dattani. New Delhi: Penguin, 2000. 381-447.

---. "Seven Steps around the Fire." Collected Plays. By Dattani. New Delhi: Penguin, 2000. $1-42$.

---.Tara. Collected Plays. By Dattani. New Delhi: Penguin, 2000. 317-80.

---. Thirty Days in September. New Delhi: Panguin, 2010.

---. “Where There's a Will.” Collected Plays.By Dattani. New Delhi: Panguin, 2000. 449511.

Secondary Sources

Karnad, Girish. Introduction to Three Plays. Naga Mandala, Hayavadana and Tughlag. The Plays of Girish Karnad: Critical Perspectives. Ed. Jaydip Singh Dohiya. New Delhi: Prestige, 1999. 5-23

Nandy, Ashis. The Intimate Enemy: Loss and Recovery of Self under Colonialism. Delhi: Oxford UP,1993. 